\title{
Lumbar (Petit's) hernia: A rare entity
}

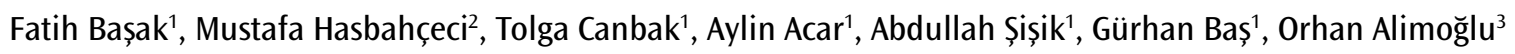

ABSTRACT Lumbar hernias are rare and diagnostically challenging for surgeons. We present the case of a middle-aged patient who presented with swelling in the left back. Subcutaneous lipoma was included in the differential diagnosis. Following diagnostic studies, computed tomography confirmed left lumbar hernia. Elective surgery was performed, and the results revealed Petit's hernia. The hernia was repaired with mesh.

Keywords: Lumbar hernia, Grynfeltt hernia, Petit's hernia

\section{Cite this paper as:} Başak F, Hasbahçeci M, Canbak T, Acar A, Şişik A, Baş G, Alimoğlu 0. Lumbar (Petit's)

hernia: A rare entity. Turk J Surg 2017; 33: 220-221.

'Clinic of General Surgery, Ümraniye Training and Research Hospital, İstanbul, Turkey 2Department of General Surgery, Bezmialem Vakif University School of Medicine, İstanbul, Turkey

${ }^{3}$ Department of General Surgery, Medeniyet University Göztepe Training and Research Hospital, İstanbul, Turkey

\section{Address for Correspondence} Fatih Başak

e-mail: fatihbasak@hotmail.com

Received: 21.11.2014

Accepted: 25.01.2015

Available Online Date: 06.07.2015

OCopyright 2017

by Turkish Surgical Association

\section{INTRODUCTION}

Lumbar hernias are rare entities. Because of their rarity and complex anatomical location, they can pose a formidable challenge to surgeons. The challenges start with diagnosis and continue to the selection of treatment $(1,2)$. In this report, our aim is to highlight the topic, present a case of Petit's hernia, and discuss anatomical information and management strategies under the guidance of literature reviews.

\section{CASE PRESENTATION}

A 52-year-old man was admitted to the general surgery clinic with a swelling in his back. His medical history included chronic obstructive lung disease. Surgical history included lumbar disc hernia surgery six years ago, diaphragm repair with left thoracotomy following trauma three years ago, and right inguinal hernia repair one year ago. Physical examination revealed a palpable, slightly tender mass $5 \mathrm{~cm}$ in diameter in the left back below the $12^{\text {th }}$ rib. The remainder of his physical examination was normal. Laboratory analyses, including tumor markers, were within normal limits. Computed tomography (CT) revealed a herniated mass extending from the lumbar space to the subcutaneous area in the left posterolateral abdominal wall (Figure 1). Considering these findings, surgical treatment was planned, and the patient (in the prone position) was electively operated on under general anesthesia. An incision was made over the mass. The latissimus dorsi muscle was retracted superiorly and the herniated fatty tissue protruding from the inferior lumbar space was exposed (Figure 2). The diagnosis of Petit's hernia was confirmed. After invagination of the herniated mass, continuous 0 polyglactin sutures were placed. A polypropylene mesh was placed over the area. The postoperative period was uneventful, and the patient was asymptomatic at the 3-month follow-up.

\section{DISCUSSION}

The lumbar region is the region of the back lateral to the vertebral region and between the rib cage and pelvis. Its borders are formed medially by the erector spinae muscles, laterally by the external oblique muscle, superiorly by the $12^{\text {th }}$ rib, and inferiorly by the iliac crest. The anatomical boundaries of the inferior and superior lumbar spaces were described by Petit and Grynfeltt in 1783 and 1866, respectively $(1,2)$. The margins of the inferior lumbar (Petit's) triangle consists of the iliac crest, the margins of the latissimus dorsi muscle, and external abdominal oblique muscles. The internal abdominal oblique muscle is observed at the floor of the inferior lumbar triangle. Borders of the superior lumbar (Grynfeltt) triangle are formed medially by the quadratus lumborum muscle, laterally by the internal abdominal oblique muscle, and superiorly by the $12^{\text {th }}$ rib. The floor of the superior lumbar triangle is formed by the transversalis fascia, and the roof is filled by the external abdominal oblique muscle $(1,2)$.

Petit's hernia is described as herniation of retroperitoneal fat through the aponeurosis of the internal abdominal oblique muscle between the erector spinae muscles in the inferior lumbar triangle. The neck of this hernia is usually large, and therefore, it has a lower risk of strangulation than other hernias (1). Grynfeltt hernia is described as herniation of retroperitoneal fat through the aponeurosis of the transversalis muscle between the erector spinae muscles and internal oblique muscles in the superior lumbar triangle (2). 


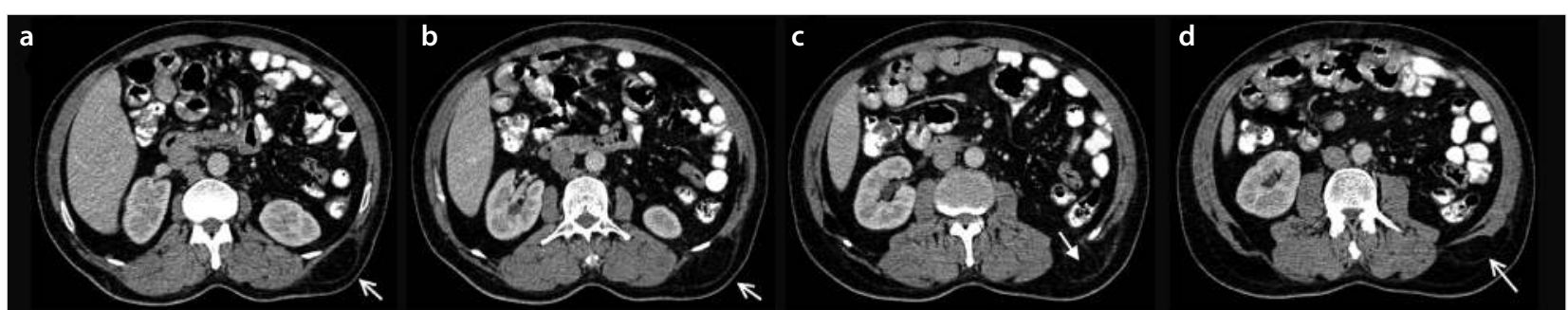

Figure 1. a-d. CT scan of the patient showing a herniated mass extending from the abdomen to the left posterolateral abdominal wall. Four CT images with 1.5-cm intervals starting from (a) to (d). White arrows in (a, b, d) show hernia. Full white arrow in (c) shows herniation through the lumbar area

$\mathrm{CT}$ : computed tomography

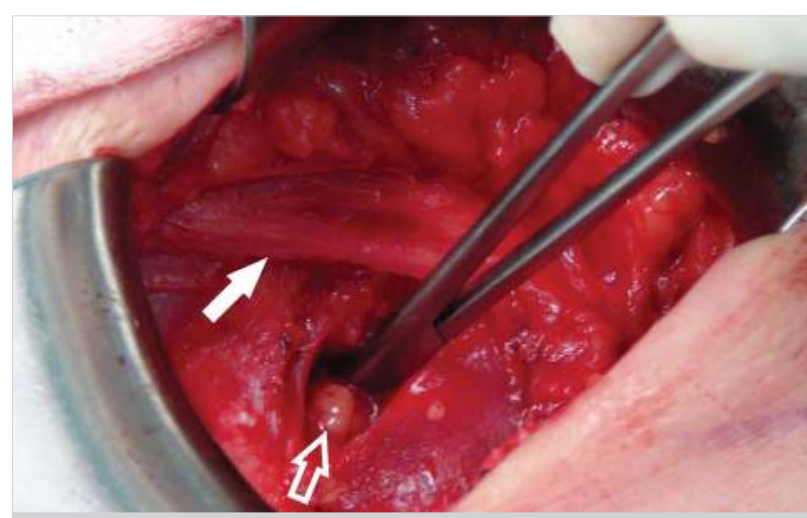

Figure 2. Lumbar hernia, perioperative image after invagination of the herniated mass Full white arrow: Latissimus dorsi muscle; empty white arrow: herniated area

Lumbar hernias are rare lesions that are usually observed after trauma or surgery. Petit's hernia occurs more often in the left side and in males $(3,4)$. In the present case, the patient was male and had a history of lumbar surgery and left-sided hernia.

There are about 300 reports in the literature; almost all reports are case reports. A general surgeon will have experienced at least a single instance of one or a few lumbar hernias in his/ her career $(5,6)$. Symptoms and presentation of lumbar hernias can vary. They are frequently asymptomatic or may cause back pain in the sciatic nerve distribution area with or without a palpable mass. According to Light, it is the most probable diagnosis in young women and athletes with back pain (7). In differential diagnoses, abscess, hematoma, lipoma, renal tumors, or muscle spasm should be considered. For imaging purposes, CT is accepted as a routine diagnostic technique to evaluate patients with lumbar hernia $(3,5)$. In the present case, $\mathrm{CT}$ revealed herniation of the mass at left lumbar spaces, verified the diagnosis, and guided the surgery.

Natural evaluation of these hernias is a steady growth in size. Surgical treatment is suggested for all lumbar hernias if allowed by the patient's general condition. Several surgical techniques, including simple closure, myoplasties, and plasties using meshes, have been identified as treatment modalities. The laparoscopic approach may be used for small and moderate hernias $(3,8)$. Although various methods have been defined in the surgical treatment of lumbar hernias, no method has been recommended as the most favorable surgical technique because of the risk of recurrence.

\section{CONCLUSION}

Lumbar hernias are rare clinical entities and need suspicion to be diagnosed. Imaging studies, particularly CT, are useful in defining the anatomy and contents. Reconstruction can be achieved with synthetic mesh repair; this can be accomplished by either open or endoscopic methods with minor complications.

Informed Consent: Written informed consent was not obtained due to retrospective nature of the case.

Peer-review: Externally peer-reviewed.

Author Contributions: Concept - F.B., M.H., T.C., A.A.; Design - F.B., M.H., A.Ş., G.B., O.A.; Supervision - F.B., M.H., G.B., O.A.; Data Collection and/ or Processing - F.B., T.C., A.A.; Analysis and/or Interpretation - F.B., M.H., G.B., O.A.; Literature Review - F.B., M.H., T.C., A.S..; Writer - F.B., M.H., A.A., A.Ş.; Critical Review - F.B., M.H., G.B., O.A.

Conflict of Interest: No conflict of interest was declared by the authors.

Financial Disclosure: The authors declared that this study has received no financial support.

\section{REFERENCES}

1. Petit JL. Traite des maladies chirurgicales, et des operations qui leur convenient, volume 2. T.F. Didot, Paris 1774: 256-258.

2. Grynfeltt J. Quelque mots sur la hernie lombaire. Montpellier Med 1866; 16: 329.

3. Suarez S, Hernandez JD. Laparoscopic repair of a lumbar hernia: report of a case and extensive review of the literature. Surg Endosc 2013; 27: 3421-3429. [CrossRef]

4. Saylam B, Duzgun AP, Ozer MV, Coskun F. Acute traumatic abdominal wall hernia after blunt trauma: A case report. Ulus Cerrahi Derg 2011; 27: 43-45. [CrossRef]

5. Moreno-Egea A, Baena EG, Calle MC, Martínez JA, Albasini JL. Controversies in the current management of lumbar hernias. Arch Surg 2007; 142: 82-88. [CrossRef]

6. Mismar A, Al-Ardah M, Albsoul N, Younes N. Underlay mesh repair for spontaneous lumbar hernia. Int J Surg Case Rep 2013; 4: 534536. [CrossRef]

7. Light HG. Hernia of the inferior lumbar space. A cause of back pain. Arch Surg 1983; 118: 1077-1080. [CrossRef]

8. Bigolin AV, Rodrigues AP, Trevisan CG, Geist AB, Coral RV, Rinaldi $\mathrm{N}$, et al. Petit lumbar hernia-a double-layer technique for tensionfree repair. Int Surg 2014; 99: 556-559. [CrossRef] 